\title{
Article \\ Thermogravimetric Analysis of Marine Gas Oil in Lubricating Oil
}

\author{
Suhyun Ahn, Jeong Mog Seo and Heejin Lee *
}

check for

updates

Citation: Ahn, S.; Seo, J.M.; Lee, H Thermogravimetric Analysis of Marine Gas Oil in Lubricating Oil. J. Mar. Sci. Eng. 2021, 9, 339. https:// doi.org/10.3390/jmse9030339

Academic Editor: Tie Li

Received: 23 February 2021

Accepted: 18 March 2021

Published: 19 March 2021

Publisher's Note: MDPI stays neutral with regard to jurisdictional claims in published maps and institutional affiliations.

Copyright: (C) 2021 by the authors. Licensee MDPI, Basel, Switzerland. This article is an open access article distributed under the terms and conditions of the Creative Commons Attribution (CC BY) license (https:// creativecommons.org/licenses/by/ $4.0 /)$.
Korea Coast Guard Research Center, Korea Coast Guard Academy, Korea Coast Guard, Cheonan 31254, Korea; ahnsh7@korea.kr (S.A.); greenjm1@korea.kr (J.M.S.)

* Correspondence: heejinlee0608@korea.kr; Tel.: +82-41-640-2151; Fax: +82-41-640-2861
Abstract: Marine lubricating oil (LO) is deteriorated by contaminants-especially marine gas oil (MGO), which is invariably mixed during its usage-that can damage engine performance. This study investigates a method for determining the content of MGO in lubricating oil. Weight loss from MGO-containing lubricant was evaluated through thermogravimetric analysis (TGA), and a standard calibration curve was plotted to establish a correlation with MGO content. A comparison of the commonly used ASTM-based gas chromatography (GC) analysis, and this TGA approach revealed that the former was more accurate when the lubricant contained $\leq 1 \% \mathrm{MGO}$; however, TGA afforded higher accuracy when the MGO content was between $0.5 \%$ and $15 \%$. Hence, TGA can be used as a simple, reliable, and rapid method to analyze the contents of a lubricant contaminant such as MGO.

Keywords: lubricating oil; marine gas oil; TGA-DTG; SAE 40; diesel

\section{Introduction}

Maritime transport plays a significant role in international merchandise transactions, forming part of a specialized, inexpensive bulk supply chain [1,2]. However, the shipping industry has become an important source of greenhouse gas (GHG) emissions in recent decades. Carbon emissions from the shipping sector worldwide account for almost $3 \%$ of total $\mathrm{CO}_{2}$ emissions. As a result, the International Maritime Organization (IMO) encourages the conservation of resources and energy using GHG reduction measures [3]. In addition, the appropriate management of engine oil not only optimizes engine performance but also helps reduce energy loss [4].

In principle, lubricating oil (LO) converts dry friction into a fluid one that reduces frictional resistance by functioning as a mediator between moving units such as the pistoncylinder assembly, crank shaft, and oil pump [5-7]. In addition, lubrication is essential for cooling through heat absorption, stress distribution, flushing, and corrosion prevention in machinery parts [8].

LO performance is affected by both internal and external factors. Factors such as oxidation and contamination by insoluble matter, including fuel, degrade the stability of LO [9]. Fuel, especially diesel, can dilute the LO through abrasion of the cylinder head and piston rings or defects in the fuel nozzle and pump [10]. In addition, diesel oil and LO inevitably blend around parts that reciprocate relative to each other, such as the pistoncylinder apparatus. As a result, intrinsic properties of the lubricant (e.g., the kinematic viscosity) change, resulting in accelerated deterioration of the oil, which can cause the engine to become overloaded and fall into disrepair [11].

Therefore, it is necessary to quantitatively determine the total amount of contaminants such as fuel in the lubricant. In general, the fuel dilution method of lubricating oil based on ASTM D 3524 [12], D 3525 [13], and D 7593 [14] is widely used. However, there are cases where the peaks cannot be separated in gas chromatography (GC) analysis because the boiling points of marine gas oil (MGO) and LO overlap. Agarwal studied the tribology of LO blended with fuels to evaluate the performance of biodiesel by determining physical 
characteristics such as moisture content and thermal properties through differential scanning calorimetry [15]. $\mathrm{Ng}$ et al. proposed an alternative approach for the determination of water in lubricants by infrared spectroscopy using solvent extraction with a titration method [16]. Macian et al. investigated the thermal and fuel-dilution effects on oils using infrared spectrometry to quantify LO oxidation. LO with even a small amount of contamination often damages the engine [17]. However, it is difficult to identify such low contamination levels. As a result, this topic has not been sufficiently investigated.

The present study aimed to quantify MGO mixed in aged LO for ships, to develop a simple, reliable, and efficient method for monitoring the degradation of LOs. The MGO contents in the LO were determined using GC as a general method and compared to the results obtained via thermogravimetric analysis (TGA). In addition, TGA was applied to Society of Automotive Engineers (SAE) 30 and 40 lubricants, and their MGO contents were determined both in the presence and absence of moisture.

\section{Materials and Methods}

\subsection{Sample Preparation}

Commercial marine LO used in high-speed diesel engines (single grade SAE 40, API $\mathrm{CF}$ ) and MGO (category ISO-F-DMA, $<0.5 \%$ sulfur) were purchased from GS Caltex, Korea. The physicochemical properties of the commercial LO and MGO were determined using the ASTM test method, the results of which are presented in Table 1. As both oils met the minimum requirements of ISO 8217:2017 [18] and MTU specifications, the oils could be used as sample references. ISO 8217:2017 (petroleum product specifications for marine fuels) specifies the requirements of physical properties for MGO; MTU, a manufacturer of commercial internal combustion engines, also provides those specifications for $\mathrm{LO}$ (fluid and lubricant specifications).

Table 1. Physicochemical properties of commercial lubricating oil (LO), marine gas oil (MGO), and spent LO.

\begin{tabular}{|c|c|c|c|c|}
\hline Property & Fresh LO & MGO & Spent LO & Test Method \\
\hline Density, $\mathrm{g} / \mathrm{cm}^{3}$ at $15^{\circ} \mathrm{C}$ & 0.8809 & 0.8755 & 0.8833 & ASTM D 4052 \\
\hline Specific gravity & 0.8817 & 0.8763 & 0.8841 & ASTM D 5052 \\
\hline Kinematic viscosity, cSt at $40^{\circ} \mathrm{C}$ & 134.27 & 3.8121 & 90.716 & ASTM D 445 \\
\hline Kinematic viscosity, cSt at $100^{\circ} \mathrm{C}$ & 14.746 & - & 11.54 & ASTM D 445 \\
\hline Viscosity index (VI) & 110.4 & - & 116.4 & ASTM D 2270 \\
\hline Pour point, ${ }^{\circ} \mathrm{C}$ & -39 & -6 & -43 & ASTM D 97 \\
\hline Flash point, ${ }^{\circ} \mathrm{C}$ & 244 & 72 & 232 & ASTM D 93 \\
\hline $\mathrm{TBN}, \mathrm{mgKOH} / \mathrm{g}$ & 12.8301 & - & 11.2581 & ASTM D 2896 \\
\hline Sulfur content, wt $\%$ & - & 0.016 & - & ASTM D 4294 \\
\hline Water content, wt $\%$ & 0.01 & $\mathrm{~N} / \mathrm{D}$ & 0.12 & ASTM D 6304 \\
\hline Color, ASTM scale & L 3.5 & L 0.5 & $\mathrm{~N} / \mathrm{A}(>8.0)$ & ASTM D 1500 \\
\hline
\end{tabular}

Samples of LO containing MGO were prepared by mixing the LO with MGO. To construct the calibration curves, LO was blended with 2, 5, 10, 20, and 50\% MGO; to assess accuracy, four different MGO concentrations $(0.5,1,3$, and $15 \%)$ were employed. To evaluate the TGA method with respect to the presence of moisture, a LO sample containing $0.5 \mathrm{wt} \%$ water and $20 \%$ MGO was also prepared.

Spent marine lubricant was obtained from the high-speed four-stroke diesel main engine (MTU) of a 1000 gross ton vessel that used the same grades of LO and MGO as the reference samples, in order to apply the proposed method to an actual case.

\subsection{Instruments and Parameters}

GC based on ASTM D 3524 [12] was used as a test method to determine the amount of diesel fuel in the lubricant. This ASTM method utilizes $n$-decane as an internal standard. Chromatographic analyses were performed with a gas chromatograph (2010, Shimadzu) equipped with a flame ionization detector (FID). The experiment was conducted using an 
RTX-1 column $(0.25 \mathrm{~mm} \times 0.25 \mu \mathrm{m} \times 15 \mathrm{~m}$, Restek) with a dimethyl polysiloxane stationary phase. A $1 \mu \mathrm{L}$ injection volume of each sample diluted to $6 \mathrm{mg} / \mathrm{mL}$ in hexane was used. The column temperature was increased from 40 to $325^{\circ} \mathrm{C}$ at a heating rate of $10^{\circ} \mathrm{C} / \mathrm{min}$ and then held constant at $325^{\circ} \mathrm{C}$ for $10 \mathrm{~min}$.

A thermogravimetric analyzer (TGA N-1000, Scinco) was used to determine the amount of MGO incorporated in the LO. Each reference and mixed sample (19-21 mg) was placed in an open aluminum pan (5.2 $\mathrm{mm}$ inner diameter $\times 2 \mathrm{~mm}$ height) and then put in the thermogravimetric analyzer for analysis. Each sample was heated to $500{ }^{\circ} \mathrm{C}$ at a heating rate of $15^{\circ} \mathrm{C} / \mathrm{min}$ while under a nitrogen atmosphere at a flow rate of $30 \mathrm{cc} / \mathrm{min}$.

\section{Results and Discussion}

\subsection{GC}

LO samples containing 2, 5, 10, 20, and 50\% MGO were analyzed as calibration mixtures by GC. The GC chromatograms of commercial LO, MGO, LO/10\% MGO, and $\mathrm{LO} / 10 \% \mathrm{MGO}$ with internal standard are shown in Figure 1 . Only $n-\mathrm{C}_{10}$ is detected at a retention time of $6.5 \mathrm{~min}$. At $17 \mathrm{~min}$, The MGO and LO peaks begin to overlap when the first peaks attributed to LO are detected. In the chromatogram, the peaks derived from the two components without any separation show a minimum overlap at $21.6 \mathrm{~min}$ when $n-C_{23}$ is identified. Therefore, the range of MGO peaks was set from 9.5 to $21.6 \mathrm{~min}$.

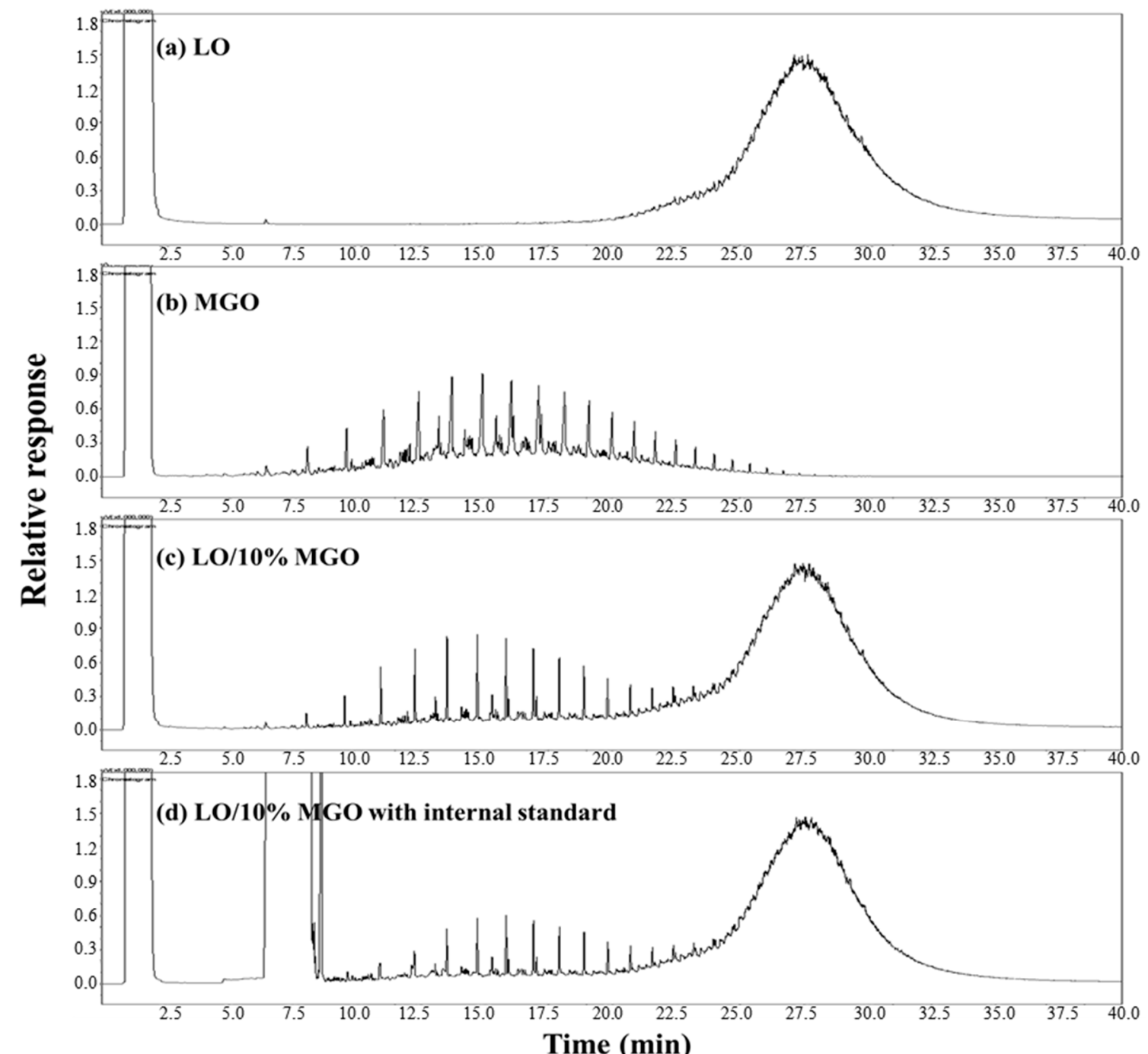

Figure 1. Gas chromatogram of (a) commercial lubricating oil (LO), (b) marine gas oil (MGO), (c) LO/10\% MGO, and (d) LO/10\% MGO with internal standard. 
In accordance with the ASTM method [12], the $R$ values (diesel area/ $n$-decane area) of samples containing 2, 5, 10, 20, and 50\% MGO were calculated as $0.00061,0.00129,0.00155$, 0.00351 , and 0.00851 , respectively, using the total area of the MGO peak and area for $n$ decane. All samples were measured in triplicate, and the standard deviations were within $5.77 \times 10^{-5}$, the highest one for $R$ value. The calibration curve for the MGO mixing ratio and $R$ value correlate well with a linear fit $\left(r^{2}=0.9959\right)$, thus indicating a linear equation $(y=0.00016 x+0.00023)$.

The four blended MGO/LO test samples (0.5, 1, 3, and $15 \% \mathrm{MGO})$ were then evaluated by the GC method. The measured MGO contents based on the standard calibration curve are shown in Figure 2. Analyses of mixed samples with $<1 \%$ MGO in the LO are very accurate, whereas when the MGO content is $\geq 3 \%$, a large difference from the actual value is observed; as the MGO concentration increases, it is difficult to completely separate the MGO and LO peaks. As a consequence, only low concentrations of MGO can be accurately identified. Note that the ASTM D 3524 method can be used only when the lubricant contains 0-12 mass\% diesel fuel.

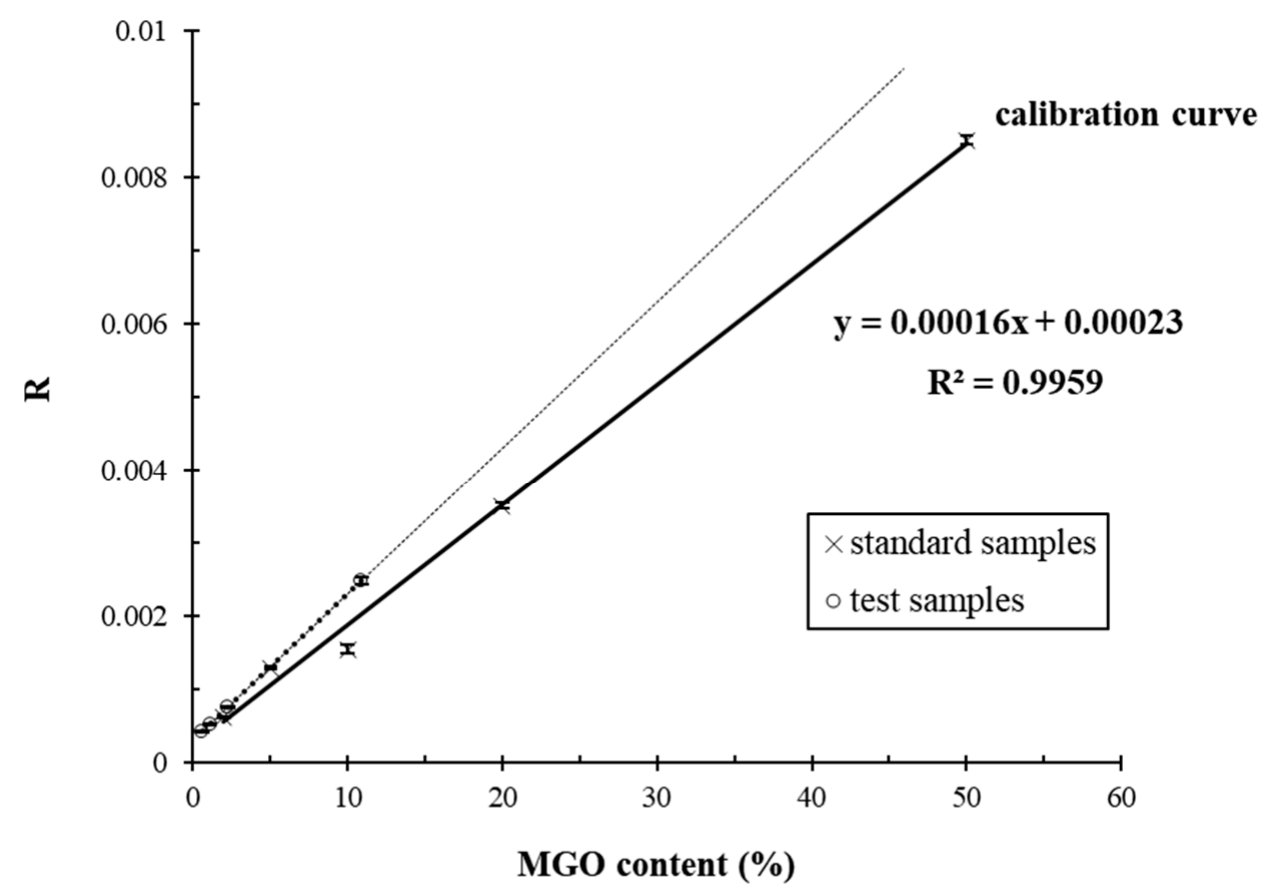

Figure 2. Comparison of the true and measured values $(R=$ diesel area $/ n$-decane area $)$ of the marine gas oil (MGO) content in lubricating oil (LO).

\subsection{TGA}

The TGA and derivative thermogravimetric (DTG) curves (Figure 3a,b, respectively) were obtained for fresh LO and MGO. The TGA curve of the fresh LO indicates a fast weight loss stage during which the base oil decomposes between $\sim 200$ and $390{ }^{\circ} \mathrm{C}$. During this stage, weight loss starts to increase sharply after $270{ }^{\circ} \mathrm{C}$, with decomposition complete at $430{ }^{\circ} \mathrm{C}$. Shara et al. showed that the decomposition of LO was complete at $410{ }^{\circ} \mathrm{C}$ [19]. Alam et al. reported that $\mathrm{LO}$ consists mainly of $\mathrm{C}_{18}-\mathrm{C}_{33}$ hydrocarbons, while MGO contains a significant portion of $\mathrm{C}_{11}-\mathrm{C}_{20}$ hydrocarbons [20]. Weight loss from LO occurs over a wider temperature range than MGO, thus implying a wider molecular weight distribution for LO. After heating to $500{ }^{\circ} \mathrm{C}$, carbon residues of 1.97 and $0.24 \mathrm{wt} \%$ were obtained for the LO and MGO samples, respectively. 

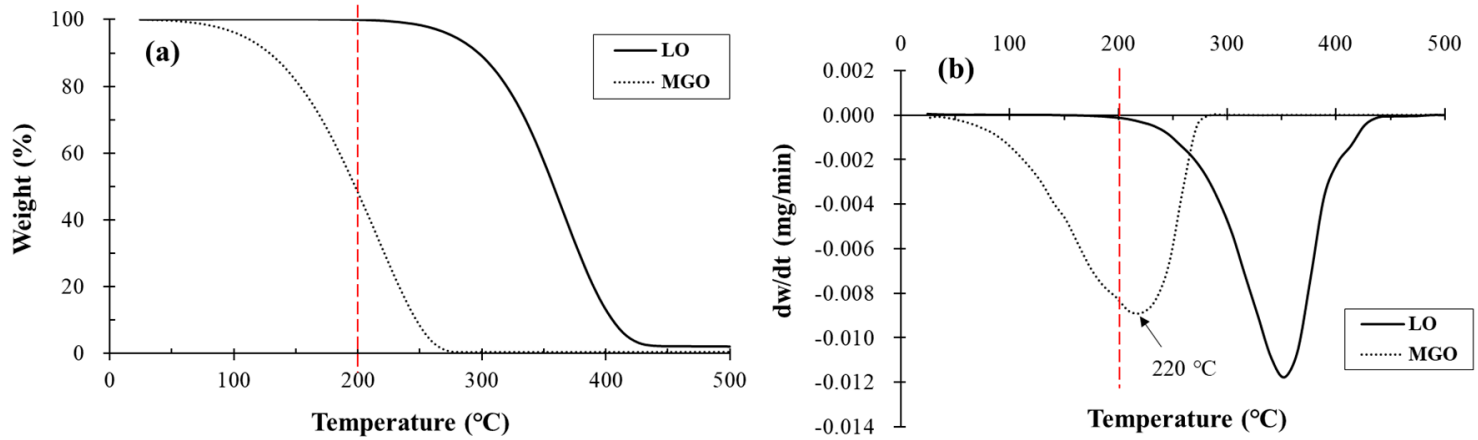

Figure 3. (a) Thermogravimetric analysis (TGA) and (b) derivative thermogravimetric (DTG) curves of lubricating oil (LO) and marine gas oil (MGO); LO starts to degrade at the temperature indicated with a red dashed line.

The DTG profile of fresh MGO reveals that its weight decreases until $275{ }^{\circ} \mathrm{C}$, with one major peak centered at $220^{\circ} \mathrm{C}$. To determine the MGO content in the mixed samples, the temperature range of $140-210^{\circ} \mathrm{C}$ was initially selected, owing to the fast decomposition rate of MGO in this region. However, because both $\mathrm{MGO}$ and $\mathrm{LO}$ degrade simultaneously in the range of $200-280^{\circ} \mathrm{C}$, an appropriate temperature for calculating the MGO content was finally selected as $140-200^{\circ} \mathrm{C}$.

The TGA and DTG results for LO samples containing MGO depend on the MGO content (Figure 4a,b). As the MGO content $(0,2,5,10,20$, and 50\%) in the LO increases, weight loss occurs at lower temperatures. In the DTG curves in Figure $4 b$, two peaks are observed in the LO samples containing MGO. MGO has a lower molecular weight than $\mathrm{LO}$, and as the content of MGO increases, the magnitude of the low-temperature peak also increases.
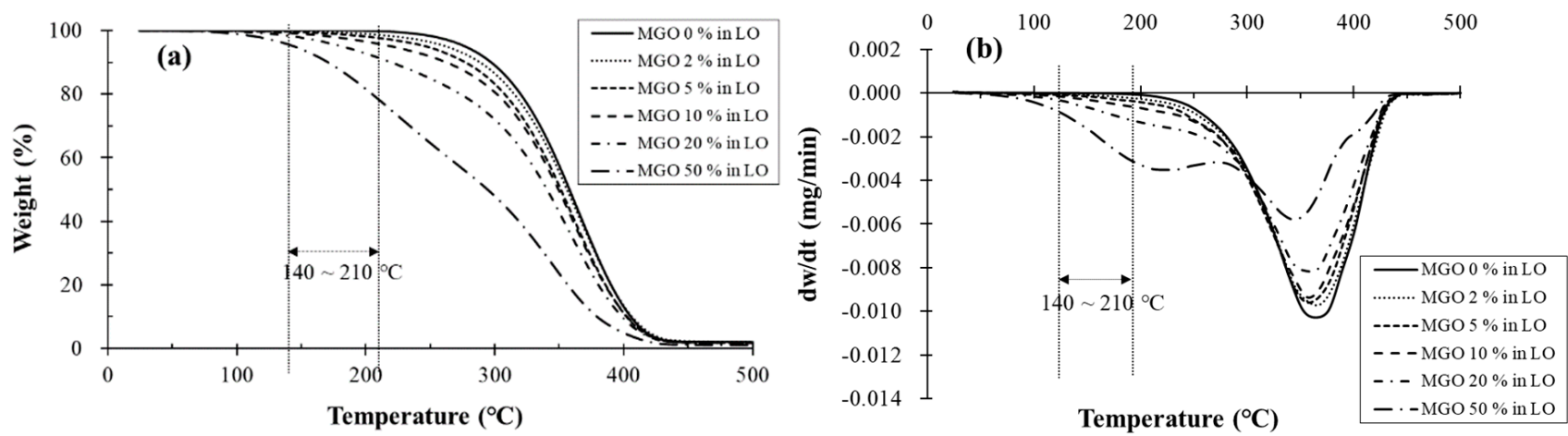

Figure 4. (a) Thermogravimetric analysis (TGA) and (b) derivative thermogravimetric (DTG) curves for standard samples (lubricating oil (LO) with 0, 2, 5, 10, 20, and 50\% marine gas oil (MGO)).

To determine the ideal temperature for investigating MGO contamination, weight losses from the standard samples were acquired from the TGA profiles in $10^{\circ} \mathrm{C}$ intervals between 140 and $210{ }^{\circ} \mathrm{C}$. The relationship between MGO concentration and weight loss from the standard samples at these specific temperatures is illustrated in Figure 5.

All of the standard calibration curves display a linear relationship between the MGO mixing ratio and weight loss. Samples were measured in triplicate, and the mean standard deviation range from 0.03 to 0.08 . The $r^{2}$ values of the standard calibration curves for the samples at $140,150,160,170,180,190,200$, and $210{ }^{\circ} \mathrm{C}$ are $0.9954,0.9976,0.9985$, $0.9991,0.9993,0.9996,0.9988$, and 0.9985 , respectively, implying good overall correlation. Measurements obtained at $\geq 170^{\circ} \mathrm{C}$ have higher $r^{2}$ values owing to sharp MGO degradation. Below $200^{\circ} \mathrm{C}$, volatilization of the $\mathrm{LO}$ is not observed and standard deviations are relatively small; a similar tendency was observed for the test samples. 


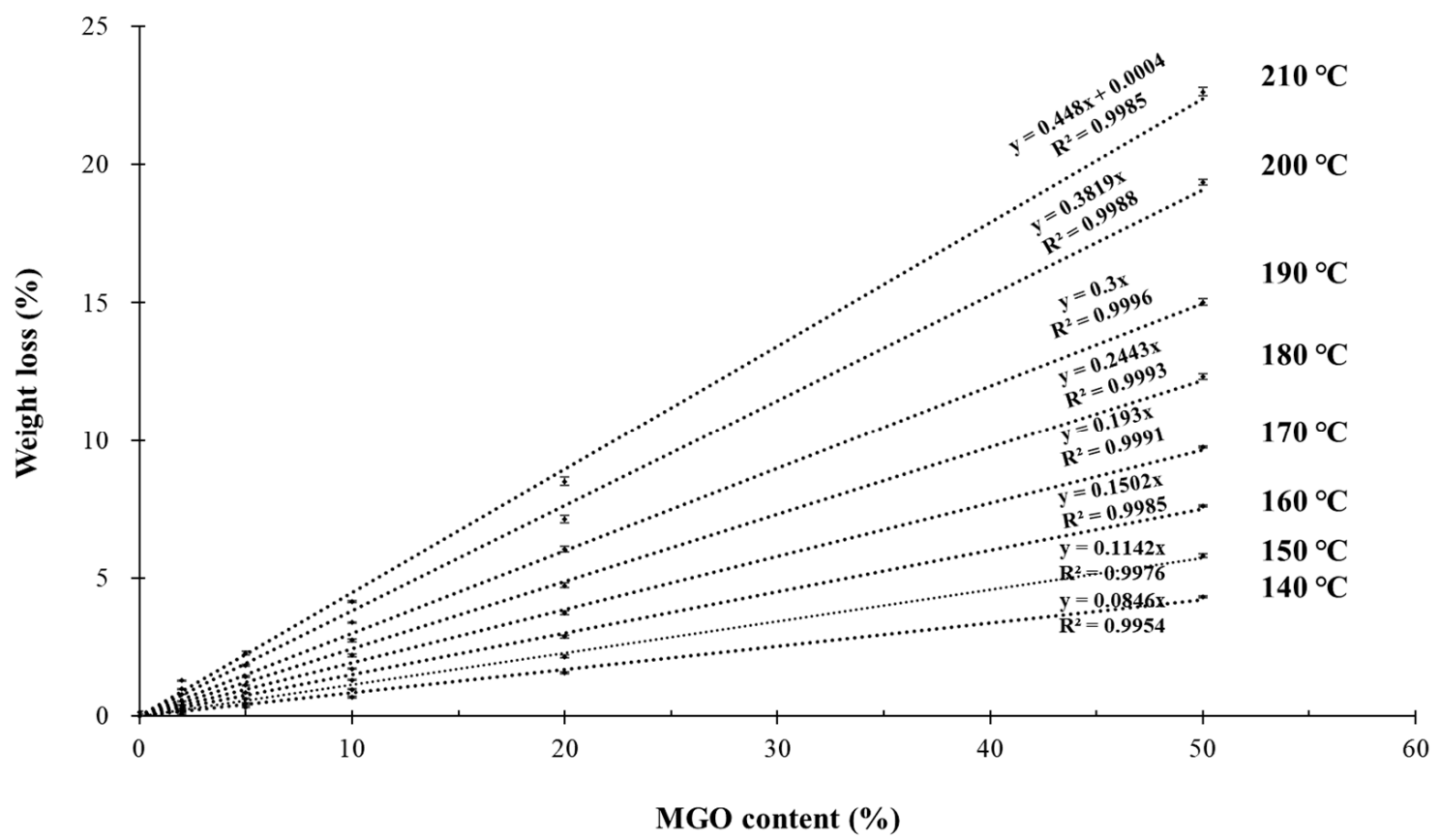

Figure 5. Standard calibration curves according to the marine gas oil (MGO) content $(0,2,5,10,20$, and $50 \%)$ in lubricating oil (LO) obtained every $10^{\circ} \mathrm{C}$ from 140 to $210^{\circ} \mathrm{C}$.

Samples of LO containing 0.5, 1, 3, and 15\% MGO were analyzed using TGA. This analysis was also carried out in triplicate, with standard deviations $<0.07$. As shown in Table 2, the MGO mixing ratios for the samples were estimated using the standard calibration curves. Temperatures from 140 to $170{ }^{\circ} \mathrm{C}$ were found to be invalid (indicated as N/A) because LO was measured when its MGO content was $<0.5 \%$. Similarly, $210^{\circ} \mathrm{C}$ could not be used because the MGO content was $<1 \%$ and LO decomposed. Both MGO and LO degraded simultaneously at $200^{\circ} \mathrm{C}$ and above. Since LO was observed at $200^{\circ} \mathrm{C}$, a temperature below $200^{\circ} \mathrm{C}$ was selected in order to obtain more accurate results for the determination of MGO content. Experimental and calculated values of MGO concentration indicated that $190^{\circ} \mathrm{C}$ is the most effective temperature for the quantitative determination of MGO content in LO.

Table 2. Calculation of MGO content in LO using the standard calibration curves.

\begin{tabular}{ccccc}
\hline \multirow{2}{*}{ Temperature $\left({ }^{\circ} \mathbf{C}\right)$} & \multicolumn{4}{c}{ MGO Content (\%) in LO } \\
\cline { 2 - 5 } & $\mathbf{0 . 5 0}$ & $\mathbf{1 . 0 0}$ & $\mathbf{3 . 0 0}$ & $\mathbf{1 5 . 0 0}$ \\
\hline 140 & $\mathrm{~N} / \mathrm{A}$ & $\mathrm{N} / \mathrm{A}$ & 1.66 & 13.64 \\
150 & $\mathrm{~N} / \mathrm{A}$ & 0.35 & 1.58 & 14.54 \\
160 & $\mathrm{~N} / \mathrm{A}$ & 0.60 & 2.00 & 14.58 \\
170 & $\mathrm{~N} / \mathrm{A}$ & 0.93 & 2.25 & 14.61 \\
180 & 0.20 & 1.15 & 2.39 & 14.41 \\
190 & 0.43 & 1.40 & 2.67 & 14.53 \\
200 & 0.60 & 1.54 & 2.72 & 13.75 \\
210 & 0.85 & 1.85 & 2.97 & 14.04 \\
\hline
\end{tabular}

The TGA-DTG profile of SAE 40 lubricant was compared with that of SAE 30 to determine whether the method could be applied to the latter. The degradation of SAE 30 begins at $194{ }^{\circ} \mathrm{C}$, i.e., before that of SAE 40 , and increases more dramatically to reach the same final temperature (Figure 6). No significant difference was observed in the weight loss of the LOs below $190^{\circ} \mathrm{C}$ for MGO determination. The measured MGO mixing ratio for 3\% MGO in the SAE 30 sample was calculated as 3.17\%. 


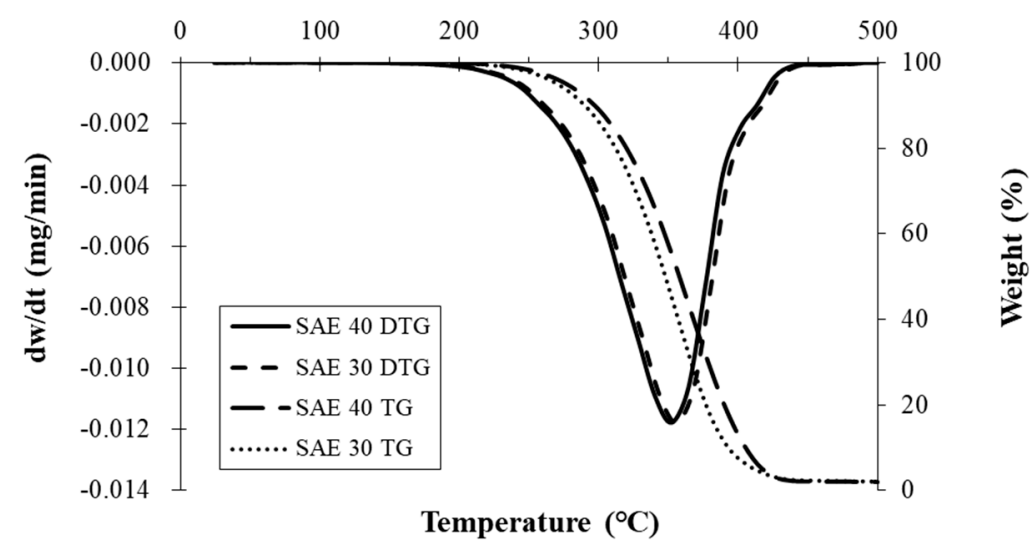

Figure 6. Thermogravimetric analysis (TGA) and derivative thermogravimetric (DTG) profiles of SAE 40 and SAE 30 lubricants.

The presence of moisture is a common phenomenon in the aging process of lubricants. The TGA method can be used to observe matrix interference caused by other contaminants, especially moisture. According to Wilson et al., few troubles are found in an engine lubricated by LO with a moisture content below $0.1 \%$ [9]. Figure 7 shows the calculated MGO content based on the presence or absence of moisture when LO contains $20 \%$ MGO. Using TGA, we compared the calibration samples of $20 \%$ MGO in LO with and without $0.5 \%$ water. At $190{ }^{\circ} \mathrm{C}$, little difference was observed in the MGO content based on the presence or absence of moisture: the MGO content was $20.10 \%$ with moisture and $20.17 \%$ without moisture, thus confirming that TGA can be used even in the presence of moisture. Idris et al. demonstrated that the TGA curve could indicate the presence of moisture below $150{ }^{\circ} \mathrm{C}$ [21]. However, MGO degradation peaks in both the TGA and DTG profiles are affected by higher moisture content. The MGO content should be carefully determined in case the oil contains a considerable amount of water.

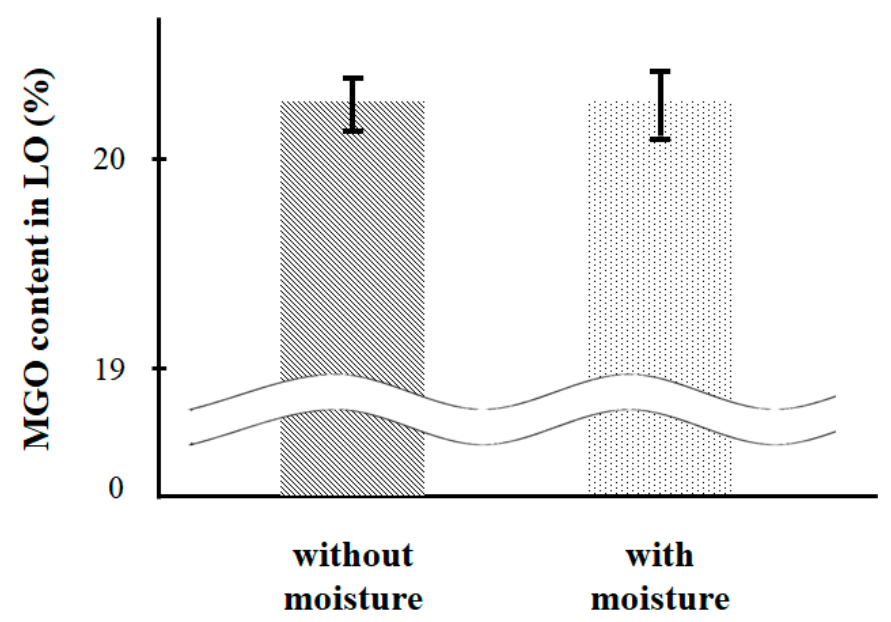

Figure 7. Comparison of marine gas oil (MGO) content in lubricating oil (LO) blends with and without moisture.

\subsection{Comparison of GC and TGA Analyses}

Table 3 lists the calculated MGO content obtained through GC and TGA analyses. A comparison of both data sets indicates that TGA is more reliable to determine the full range of MGO content present in the blended samples. However, the LO sample containing $1 \%$ MGO was measured more accurately by the GC method. These results show that GC is more suitable for investigating $\mathrm{LO}$ with low MGO content. 
Table 3. Comparison of gas chromatography (GC) and TGA methods for determining marine gas oil (MGO) content in lubricating oil (LO).

\begin{tabular}{ccccc}
\hline \multirow{2}{*}{ Method } & \multicolumn{4}{c}{ MGO Content (\%) in LO } \\
\cline { 2 - 5 } & $\mathbf{0 . 5 0}$ & $\mathbf{1 . 0 0}$ & $\mathbf{3 . 0 0}$ & $\mathbf{1 5 . 0 0}$ \\
\hline GC (ASTM D 3524) & 0.60 & 1.09 & 2.28 & 10.91 \\
TGA at $190{ }^{\circ} \mathrm{C}$ & 0.43 & 1.40 & 2.67 & 14.53 \\
\hline
\end{tabular}

In addition, TGA is simpler than the GC method when considering the process for quantifying MGO content. No special sample preparation is needed when determining MGO content with TGA, whereas clean up or dilution is necessary for GC in order to maintain instrument performance. MGO content is determined from weight loss of a sample at $190^{\circ} \mathrm{C}$ in TGA, while the $R$ value can be obtained from GC using a further calculation.

\subsection{Application to an Actual Case}

Actual spent lubricant from a main engine was analyzed in triplicate to quantitatively determine MGO contamination by applying the GC and TGA methods. As expected, in the GC chromatogram (Figure 8), the MGO and LO peaks are not completely separated. MGO peaks of up to $n-C_{28}$ can be identified at a retention time of $24.2 \mathrm{~min}$, including the range of peaks from $n-C_{11}$ to $n-C_{24}$, which appear to be isolated from the LO peak. The mean $R$ value was 0.00092 with a standard deviation of $1.31 \times 10^{-5}$. The MGO content was determined to be $3.62 \%$ based on the calibration curve.

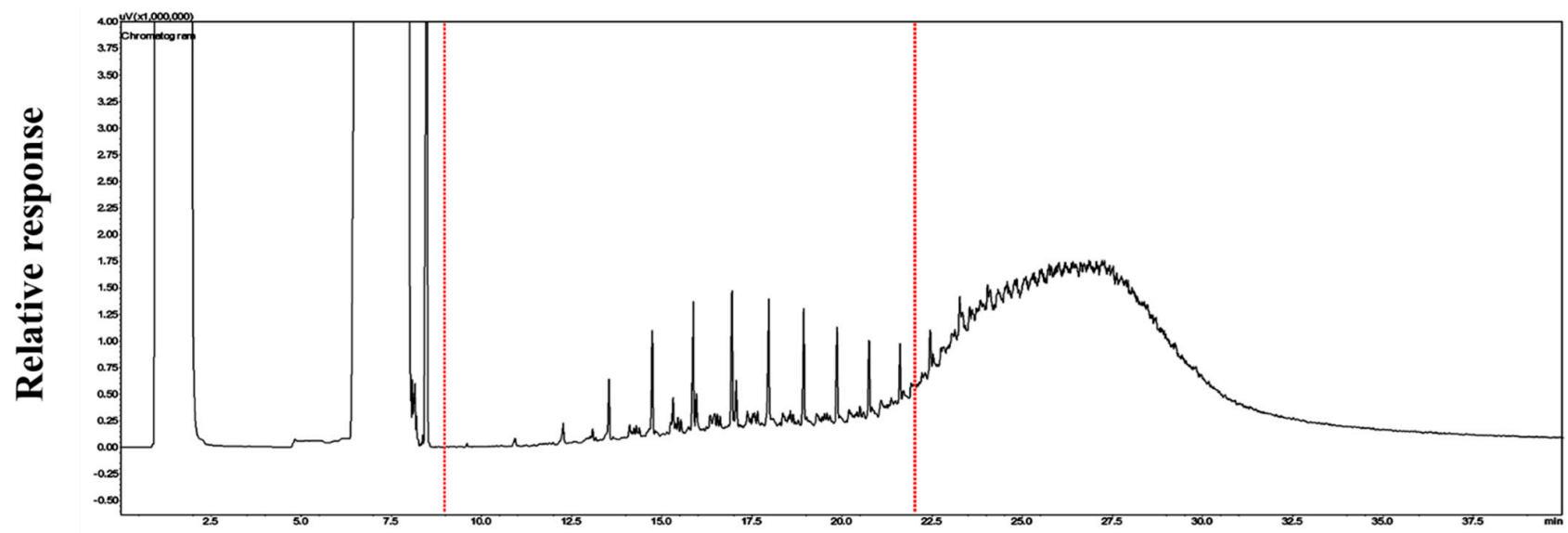

\section{Time (min)}

Figure 8. GC chromatogram of the spent lubricant.

The TGA and DTG curves of the spent LO sample are shown in Figure 9. The profiles do not exhibit a peak attributable to MGO in the temperature range of $0-275{ }^{\circ} \mathrm{C}$; thus, the LO contains less than $20 \%$ MGO when compared to commercial LO. In the DTG curve, although the peak at $417{ }^{\circ} \mathrm{C}$ represents prominent degradation of additives in the LO according to Shara et al., it does not influence the determination of MGO content [19]. MGO content in the spent LO was calculated as $4.13 \%$ (standard deviation of $0.03 \%$ ) using the calibration curve equation at $190^{\circ} \mathrm{C}$.

MGO contaminations in the spent LO were $3.62 \%$ and $4.13 \%$, as determined by GC and TGA analyses, respectively; no significant difference between the values was identified. As TGA was validated to be applicable to the actual case as well as simulated lubricants, it can be used as an alternative to the GC method. 


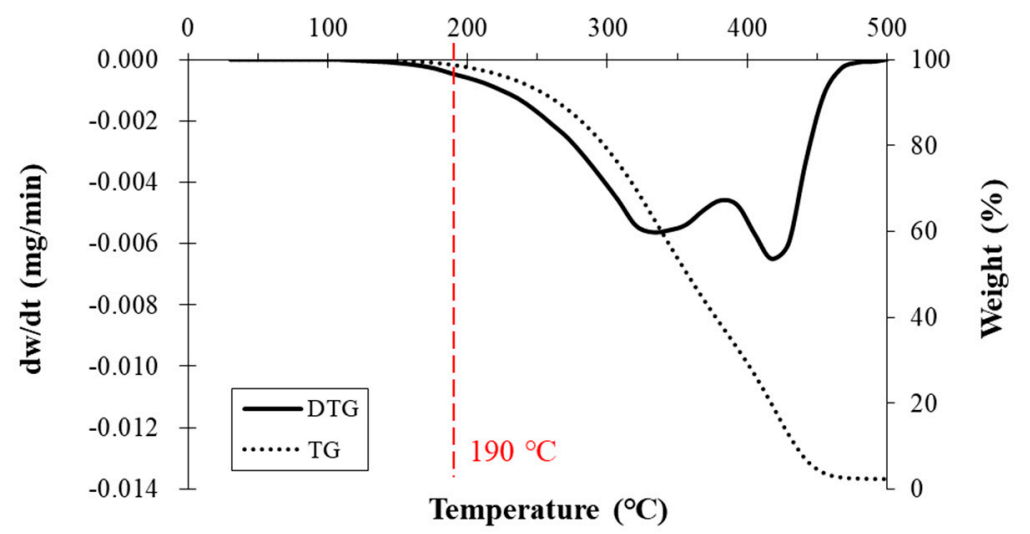

Figure 9. Thermogravimetric analysis (TGA) and derivative thermogravimetric (DTG) profiles of the spent lubricant.

\section{Conclusions}

GC is a common method to quantify the MGO content in a LO. However, this method is generally used only when the MGO content is less than $12 \%$. In addition, the content may vary based on the GC peak integration method used.

As an additionally verifiable method, TGA was evaluated and found to be a simple and reliable method for determining the MGO content in LO. Standard calibration curves based on the MGO content in the LO and the TGA weight loss were plotted. The MGO contents in the $\mathrm{LO}$ were determined to be $0.5-15 \%$ with high accuracy; similar values were obtained from GC analysis based on the ASTM D 3524 method. The applicability of TGA was confirmed using both SAE 30 and moisture-containing lubricant samples. For actual sample analysis, spent LO from a marine engine was subjected to both GC and TGA analyses, with no significant difference in MGO content. Hence, the content of MGO in LO can be measured simply and accurately using TGA as an alternative method to GC. In the future, further work will be needed to verify the applicability of TGA for analysis of more types of LOs used in marine engines.

Author Contributions: Conceptualization, S.A., J.M.S., and H.L.; methodology, S.A. and H.L.; data collection, S.A. and H.L.; data analysis, S.A., J.M.S. and H.L.; writing—original draft preparation, S.A.; internal review, H.L. All authors have read and agreed to the published version of the manuscript.

Funding: This research received no external funding.

Acknowledgments: We would like to thank Korea Coast Guard officers affiliated to Equipment Management Division of Headquarters and Stations for providing the oil samples.

Conflicts of Interest: The authors declare no conflict of interest.

\section{References}

1. Clark, X.; Dollar, D.; Micco, A. Port Efficiency, Maritime Transport Costs and Bilateral Trade. Port efficiency, maritime transport costs, and bilateral trade. J. Dev. Econ. 2004, 75, 417-450. [CrossRef]

2. UNCTAD (United Nations Conference on Trade and Development). Review of Maritime Transport 2019; United Nations Publication: New York, NY, USA; Geneva, Switzerland, 2019.

3. IMO MEPC 72. Initial Strategy on Green House Gas Emissions Reduction for Ships; MEPC/72/17; IMO International Maritime Organisation: London, UK, 2018.

4. Kovach, J.T.; Tsakiris, E.A.; Wong, L.T. Engine Friction Reduction for Improved Fuel Economy. SAE Tech. Pap. Ser. 1982. [CrossRef]

5. Kuhn, E.; Balan, C. Experimental procedure for the evaluation of the friction energy of lubricating greases. Wear 1997, 209, 237-240. [CrossRef]

6. Livanos, G.A.; Kyrtatos, N.P. Friction model of a marine diesel engine piston assembly. Tribol. Int. 2007, 40, 1441-1453. [CrossRef]

7. Millington, B.W.; Hartles, E.R. frictional losses in diesel engines. SAE Tech. Pap. Ser. 1968. [CrossRef]

8. Wang, Y.; Liang, X.; Shu, G.; Wang, X.; Bao, J.; Liu, C. Effect of lubricating oil additive package on the characterization of diesel particles. Appl. Energy 2014, 136, 682-691. [CrossRef]

9. Wilson, R.; Lyon, S. Corrosion in Lubricants/Fuels*. Shreir's Corros. 2010, 1299-1307. [CrossRef] 
10. Needelman, W.M.; Madhavan, P.V. Review of Lubricant Contamination and Diesel Engine Wear. SAE Tech. Pap. Ser. 1988. Available online: http:/ / citeseerx.ist.psu.edu/viewdoc/download?doi=10.1.1.404.7165\&rep=rep1\&type=pdf (accessed on 10 March 2001).

11. Newell, G.E. Oil analysis cost-effective machine condition monitoring technique. Ind. Lubr. Tribol. 1999, 51, 119-124. [CrossRef]

12. Standard Test Method for Diesel Fuel Diluent in Used Diesel Engine Oils by Gas Chromatography. Available online: https: //www.astm.org/Standards/D3524.html (accessed on 10 March 2001).

13. Standard Test Method for Gasoline Fuel Dilution in Used Gasoline Engine Oils by Wide-Bore Capillary Gas Chromatography. Available online: https:/ / www.astm.org/Standards/D3525.htm (accessed on 10 March 2001).

14. Standard Test Method for Determination of Fuel Dilution for in Service Engine Oils by Gas Chromatography. Available online: https:/ / www.astm.org/Standards/D7593.htm (accessed on 10 March 2001).

15. Agarwal, A.K. Experimental investigations of the effect of biodiesel utilization on lubricating oil tribology in diesel engines. Proc. Inst. Mech. Eng. Part. D J. Automob. Eng. 2005, 219, 703-713. [CrossRef]

16. Ng, E.-P.; Mintova, S. Quantitative moisture measurements in lubricating oils by FTIR spectroscopy combined with solvent extraction approach. Microchem. J. 2011, 98, 177-185. [CrossRef]

17. Macián, V.; Tormos, B.; Gómez, Y.A.; Salavert, J.M. Proposal of an FTIR Methodology to Monitor Oxidation Level in Used Engine Oils: Effects of Thermal Degradation and Fuel Dilution. Tribol. Trans. 2012, 55, 872-882. [CrossRef]

18. ISO 8217:2017 Petroleum Products-Fuels (class F)- Specification of Marine Fuels. Available online: https://www.iso.org/ standard/64247.html (accessed on 10 March 2001).

19. Shara, S.; Eissa, E.; Basta, J. Polymers additive for improving the flow properties of lubricating oil. Egypt. J. Pet. 2018, 27, 795-799. [CrossRef]

20. Alam, M.S.; Zeraati-Rezaei, S.; Liang, Z.; Stark, C.; Xu, H.; MacKenzie, A.R.; Harrison, R.M. Mapping and quantifying isomer sets of hydrocarbons ( $\geq$ C12) in diesel exhaust, lubricating oil and diesel fuel samples using GC $\times$ GC-ToF-MS. Atmos. Meas. Tech. 2018, 11, 3047-3058. [CrossRef]

21. Idris, S.S.; Rahman, N.A.; Ismail, K.; Alias, A.B.; Rashid, Z.A.; Aris, M.J. Investigation on thermochemical behaviour of low rank Malaysian coal, oil palm biomass and their blends during pyrolysis via thermogravimetric analysis (TGA). Bioresour. Technol. 2010, 101, 4584-4592. [CrossRef] [PubMed] 